диции: матер. междунар. науч. конф. СПб.: ИИМК PAH, 2015. C. 183-189.

10. Лычагина Е.Л., Митрошин Е.Н., Поплевко Г.Н. Сравнительная характеристика каменного инвентаря неолитических памятников Верхнего и Среднего Прикамья // Археология, этнография и антропология Евразии. 2017. № 4. С. 25-34.

11. Аськеев И.В., Аськеев О.В., Галимова Д.Н. Природная среда человека в Волго-Камье и Предуралье (поздний палеолит - средневековье) // Среднее Поволжье и Южный Урал: человек и природа в древности. Казань: АН РТ, 2009. С. 32-112.

12. Чагин Г.Н. Колва, Чусовское, Печора: история, культура, быт от древности до 1917 г. Пермь: Изд-во «Пушка», 2017. 672 с.

13. Крыласова Н.Б. Отчет о раскопках селища Запоселье I в Соликамском районе Пермской области в 2007 г. Пермь, 2008. Архив ЛАЭИ ПГГПУ.

14. Колчин Б.А. Ремесло // Древняя Русь: город, замок, село. М.: Наука, 1985. С. 243-297.

15. Талицкая И.А. Материалы к археологической карте бассейна р. Камы // Материалы и исследования по археологии СССР. № 27. М.: Наука, 1952. 224 с.

16. Кирьянов И.К., Коренюк С.Н., Чагин Г.Н. Рыболовство в Пермском крае в стародавние времена. Пермь: Изд-во «Книжный мир», 2007. 166 с.
17. Куза А.В. Рыбный промысел в Древней Руси. М.; СПб.: Нестор-История, 2016. 208 с.

18. Косинцев П.А. Костные останки животных из средневековых археологических памятников восточного побережья Чашкинского озера // Крыласова Н.Б., Лычагина Е.Л., Белавин А.М., Скорнякова С.В. Археологические памятники Чашкинского озера: монография. Пермь: Перм. гос. гуманит.-пед. ун-т, 2014. C. $524-529$.

19. Лычагина Е.Л., Сарапулов А.Н., Митрошин Е.Н. Рыболовный инвентарь по археологическим материалам Чашкинского микрорегиона // Стратегии жизнеобеспечения в каменном веке, прямые и косвенные свидетельства рыболовства и собирательства: матер. междунар. науч. конф. Санкт-Петербург, 15-18 мая 2018 г. СПб.: ИИМК РАН, 2018. С. 159-161.

Статья публикуется при поддержке грантов РГНФ проект № 17-11-59004а/У «Неолитизация Верхнего и Среднего Прикамья: основные подходы и методы исследования" и РФФИ проект № 1746-590037 «Ландиафты речных бассейнов и древний человек: освоение Верхней Камы в голоцене»; проект 17-46-590780 «Хозяйственно-культурный облик средневекового Предуралья (комплексное исследование)».

\title{
FISHERIES ON CHASHKINO MICRO-REGION ARCHAEOLOGICAL SITES
}

(C) 2018

Lychagina Evgeniya Leonidovna, candidate of historical sciences, associate professor of Ancient and Middle History of Russia Department

Sarapulov Aleksey Nikolaevich, candidate of historical sciences, associate professor, head of Ancient and Middle History of Russia Department Perm State Humanitarian Pedagogical University (Perm, Russian Federation)

Abstract. Chashkinskoye Lake is the Kama river palaeochannel. More than 20 archaeological sites are known on its eastern shore. They refer to the Mesolithic, Neolithic, Chalcolithic and Middle Ages. We divided all the tools that could be used for fishing in the Stone Age, into the tools directly and indirectly indicative of the development of fishing. We refer to the direct signs - the finds of sinkers and ice-splitting tools. We believe that the indirect signs include finds of axes, adzes and chisels that could be used to make boats. To this group we also include liners of composite throwing tools that could be used as harpoon blades. Mesolithic sites with tools associated with fishing were not found. On Neolithic and Chalcolithic sites large sinkers, chisels, adzes were found. This indicates that during the Neolithic-Chalcolithic period, fishing began to play an increasingly important role in the economic structure of the Chashkino micro-region population. In Middle Age settlements fishhooks, leisters, sinkers were found. The main forms of fishing were the spicy fishing, the setting up of nets and individual fishing with fishing rods.

Keywords: fishing; Kama Neolithic culture; Volgo-Kama Neolithic culture; Garino Chalcolithic Culture; Middle Ages; Lomovatovskaya culture; Rodanovskaya culture; Middle Cis-Urals; paleochannel analysis; sinker; ice-splitting tool; jail; fishing hooks; individual fishing; collective fishing.

\section{УДК 902}

DOI 10.24411/2309-4370-2018-14205

Статья поступила в редакцию 29.08.2018

\section{РЫБОЛОВСТВО В ТОБОЛО-ИШИМЬЕ В ЭПОХУ НЕОЛИТА И РАННЕГО МЕТАЛЛА} (C) 2018

Зах Виктор Алексеевич, доктор исторических наук, заведующий сектором археологических и природных реконструкций Тюменский научный цеентр СО РАН (2. Тюмень, Российская Федерация)

Аннотация. Ландшафты Тоболо-Ишимья в голоцене не были стабильны и менялись от лесов и обводненной поймы в начале V и III тыс. до н.э. до остепненных пространств с пониженным уровнем вод в начале атлантического и середине суббореального периода, что определяло основные типы хозяйства, среди которых было рыболовство. Изменение гидрологического режима водоемов влияло на способы лова рыбы, в том числе на применение различного рода ловушек. Так, в неолите, с уменьшением уровня воды, расположение поселков в системе река-протока-озеро (например, Мергень 6), большое количество костей рыб, костяные гарпуны, остроги, жерлицы и полное отсутствие грузил свидетельствуют об индивидуальном лове крупной ры- 
3ax B.A.

бы и, вероятно, запорном рыболовстве, чему способствовало уменьшение ширины проток и перейм. Рыболовство с применением запоров (заколов) привело к оседлости населения, коллективной форме деятельности и появлению долговременных поселений с глубокими котлованами жилищ. С повышением уровня воды в реках и озерах, увеличением частоты половодий меняется система жизнеобеспечения, шире осваиваются побережья водоемов, возрастает подвижность населения, сооружаются каркасные наземные жилища. На фоне этих изменений в III и начале II тыс. до н.э. в Притоболье и на сопредельных западных и северо-западных территориях появляются глиняные грузила биконической, сигаровидной и рожковидной форм. При высокой воде продуктивной становится ловля рыбы разнообразными ловушками, неводами и, вероятно, сетями, хотя последние могли использоваться и для загонной охоты на линяющих гусей и уток. С начала II тыс. до н.э. бытуют грузила подпрямоугольной формы с одним или двумя перехватами для крепления и дисковидные с перехватом по центру; они просуществовали вплоть до первой трети I тыс. до н.э. В этот период, в переходное время от бронзового к раннему железному веку, при наличии большого скопления чешуи и костей рыбы в слоях поселений, глиняные грузила отсутствуют. Не исключено, что население этого времени (местное позднебронзовое, смешанное с северными мигрантами, изготовлявшими посуду с крестовой орнаментацией) перешло от сетевого рыболовства к запорному.

Ключевые слова: Западная Сибирь; Тоболо-Ишимское междуречье; озерные системы; неолит; эпоха раннего металла; поздняя бронза; переходное время от бронзы к раннему железу; гидрологический режим; волноприбойные уступы; запорное и сетевое рыболовство; запоры (заколы); гарпуны; ловушки; глиняные грузила; охота на водоплавающую дичь.

\section{Введение}

Тоболо-Ишимье занимает лесостепную и южнотаежную зоны территории, расположенной между Уралом и Иртышом. Это равнинные пространства с высотными отметками от 60 м в северной части до 140 м на юге. В западной и восточной частях Тоболо-Ишимья протекает Тобол с широкой долиной, особенно в устьях крупных притоков - Исеть, Пышма, Тура, Тап, с прекрасными лугами, со множеством старичных и проточных озер. Уникальны с точки зрения благоприятных условий для заселения человеком система Андреевских озер (рис. 1: 2), Ишим с долиной, в которой находятся озера Мергень (рис. 1: 3), Кислое, Травное, Кабанье - остатки древнего стока, местами соединенные с современным руслом. Между Тоболом и Ишимом изобилуют озера, представляющие собой остатки древнего плейстоценового стока, и участки современных русел Вагая и Емца (рис. 1: 1). Междуречье сложено в основном суглинками, в восточной части в рельефе присутствуют гривы, поверхность между которыми часто заболочена. Наряду с пресными озерами встречаются соленые или горько-соленые водоемы. На гривах, высоких надпойменных террасах, отмечаются березовые, смешанные березово-осиновые или березово-сосновые колки. Наряду с крупными копытными: лосями, косулями и кабанами, обитающими в лесостепи, в северной части междуречья встречаются медведи. Из мелких млекопитающих на территории между Тоболом и Ишимом обитают волки, лисы, зайцы, бобры, а из боровой птицы - глухари, тетерева, куропатки и рябчики. Особенно большим разнообразием видов отличаются водно-болотные территории. На озерах с обильной кормовой базой в лесостепной части междуречья гнездятся лебеди, гуси, различные виды утиных - серая утка, шилохвость, широконоска, лысуха; в прибрежной части озер и на прилегающих лугах обитают вальдшнепы, кроншнепы и другие виды. В реках и проточных озерных системах наиболее представительными являются в основном щука, язь, окунь и карась (рис. 1: 4-7).

Эпоха неолита и раннего металла в ТоболоИшимском междуречье приходится в основном на атлантический и суббореальный периоды голоцена, охватывая более пяти тысячелетий, включая комплексы от раннего неолита до поздней бронзы. В этот отрезок времени отмечаются в основном две за- сушливых фазы - в первой половине атлантического и середине суббореального периода и три фазы увлажнения, относящиеся к началу атлантического, началу и концу суббореального периода. Кроме того, происходили колебания (усыхание и увлажнение) уровня озер в соответствии с циклами, выделенными для западно-сибирских озер А.В. Шнитниковым [1; 2]. Но, несмотря на обилие обитающих в ТоболоИшимском междуречье промысловых видов животных, территория обладает ограниченными пищевыми ресурсами, объем которых к тому же варьировался в такт периодическим изменениям климата и гидрологического режима водоемов. В этих условиях древние коллективы, адаптируясь к природно-климатическим условиям, выработали определенные системы жизнеобеспечения, но, независимо от типа хозяйства (присваивающего или производящего), рыболовство играло в них заметную, а в обществах с присваивающей экономикой - скорее всего, ведущую роль.

\section{Материал и методы исследования}

Имеется несколько типов источников, прямых и косвенных, указывающих на присутствие рыболовства в древних системах жизнеобеспечения и возможность применения определенных способов лова рыбы. Общим важным показателем существования рыболовства в обществах всех археологических периодов является расположение у водоемов и гипсометрическое положение поселков. Прямым свидетельством можно считать наличие в культурном слое поселений значительного количества костных остатков и чешуи рыбы, а также орудий лова или изделий, входящих в их состав: гарпунов, острог, рыболовных крючков, грузил, многие из которых могли иметь двойное назначение. К сожалению, песчаные и супесчаные почвы, слагающие боровые надпойменные террасы и склоны рек Тобола и Ишима, на которых в основном находятся поселения неолита - бронзы, не способствуют сохранению остеологических материалов и орудий из органических материалов. Тем не менее в Тоболо-Ишимье имеются немногочисленные поселения, на которых сохранилась кость, среди них выделяются расположенные на северо-восточном берегу оз. Мергень в Приишимье.

Источники, свидетельствующие о рыболовстве в эпоху неолита, немногочисленны, представлены в основном остеологическими материалами и костяными орудиями лова рыбы с двух многослойных по- 
3ax B.A.

Рыболовство в Тоболо-Ишимье в эпоху неолита и раннего металла

07.00.00 - исторические науки и археология

селений Мергень 5 и 6, содержащих боборыкинский и кошкинский комплексы, а также материалы эпохи раннего металла и переходного от бронзы к железу времени. Благодаря низкому гипсометрическому положению последнего неолитического поселка с долговременными жилищами на мысу у истока р. Мергеньки из оз. Мергень и многократным последующим подтоплениям и перекрываниям глинистыми речными отложениями культурного слоя, в нем хорошо сохранилась ребра, позвонки, а также чешуя, жаберные крышки рыбы и орудия для ее лова: костяные гарпуны, остроги и, возможно, «жерлицы» (рис. 2: 2-5). Судя по костным остаткам и чешуе, добывались карась, язь, окунь и щука, причем главным объектом промысла был карась $(90,5 \%)$, остальные виды имели второстепенное значение. Размер экземпляров рыбы, вылавливавшейся на обоих поселениях, одинаков, но наиболее чаще встречаются особи карповых с длиной тела 20-25 см, а щука достигала размеров 30-45 см [3, с. 103, 104]. Стабильность параметров отловленной рыбы может свидетельствовать как о размерах основной части популяции, участвовавшей в воспроизводстве, так и об одинаковых орудиях лова, существовавших у населения неолитических поселков. На остальных ранних поселениях остеологические материалы и орудия из кости практически отсутствуют.

На большинстве поселений эпохи раннего металла Тоболо-Ишимья (кроме комплексов Мергень 5 и 6) кости и чешуя рыбы в жилищах и ямах, как правило, редкое явление [4; 5], но, возможно, с рыболовством связаны фиксируемые в материалах поселений ряда культур Притоболья в большом количестве глиняные грузила. В заполнениях жилищ и ямах эпохи раннего металла на Мергене 5 и 6, как и в неолитических поселках, встречается масса рыбьих костей, жаберных крышек и чешуи, тех же пород и размеров, что вылавливались в неолитическое время $[3$, c. 103,104$]$. Из орудий лова в слоях раннего металла встречены целый гарпун и обломок гарпуна из кости [6, с. 95] и костяное орудие для чистки рыбы [7, с. 29]. Глиняные грузила на поселениях Приишимья не обнаружены, а возможно, населением этого района они и не применялись.

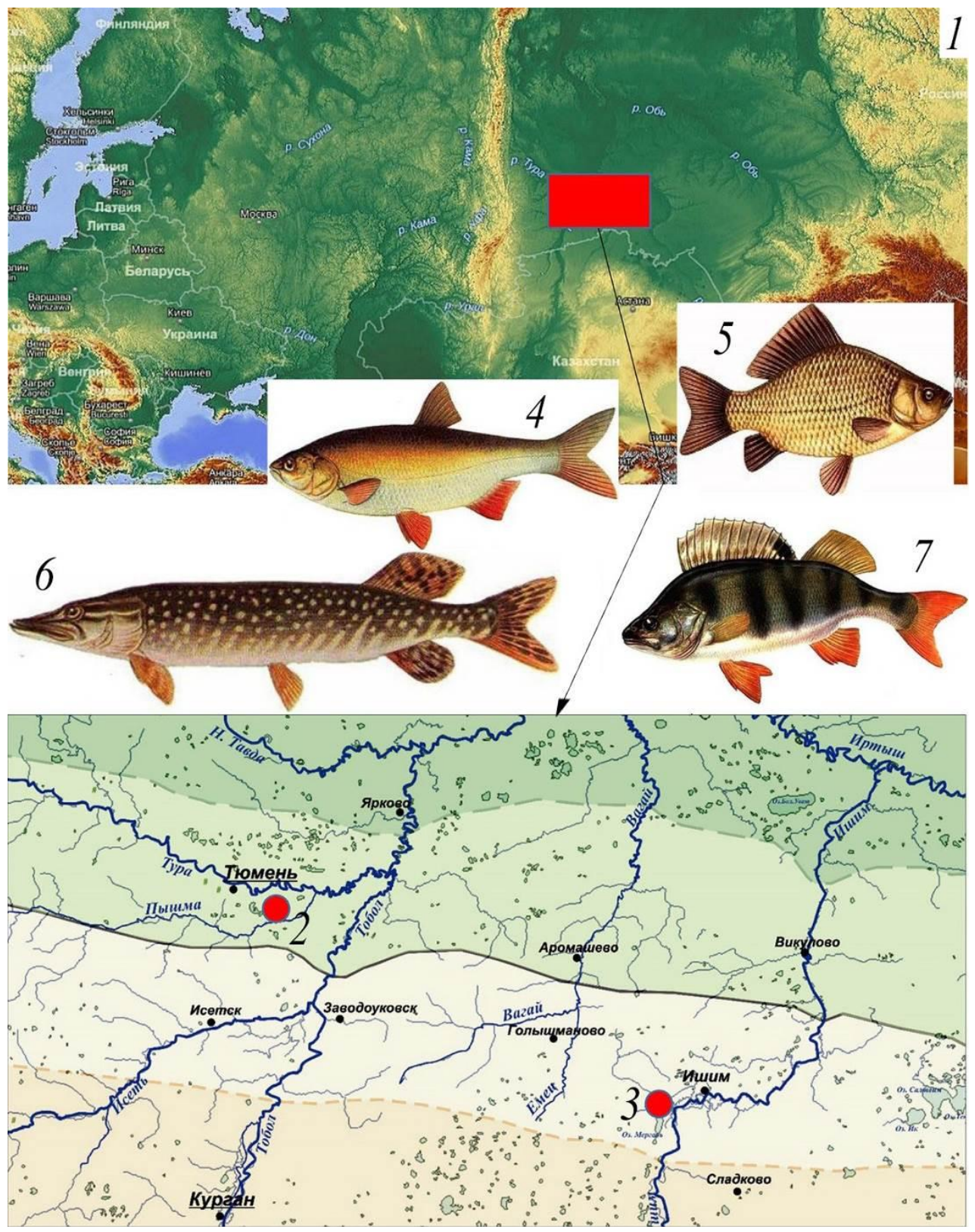

Рисунок 1 - 1 - Расположение Тоболо-Ишимского междуречья;

2- система Андреевских озер; 3- Мергеньский микрорайон; виды рыбы, добываемые в неолитическое время: 4- язь, 5-карась, 6- щука, 7- окунь 
3ax B.A.
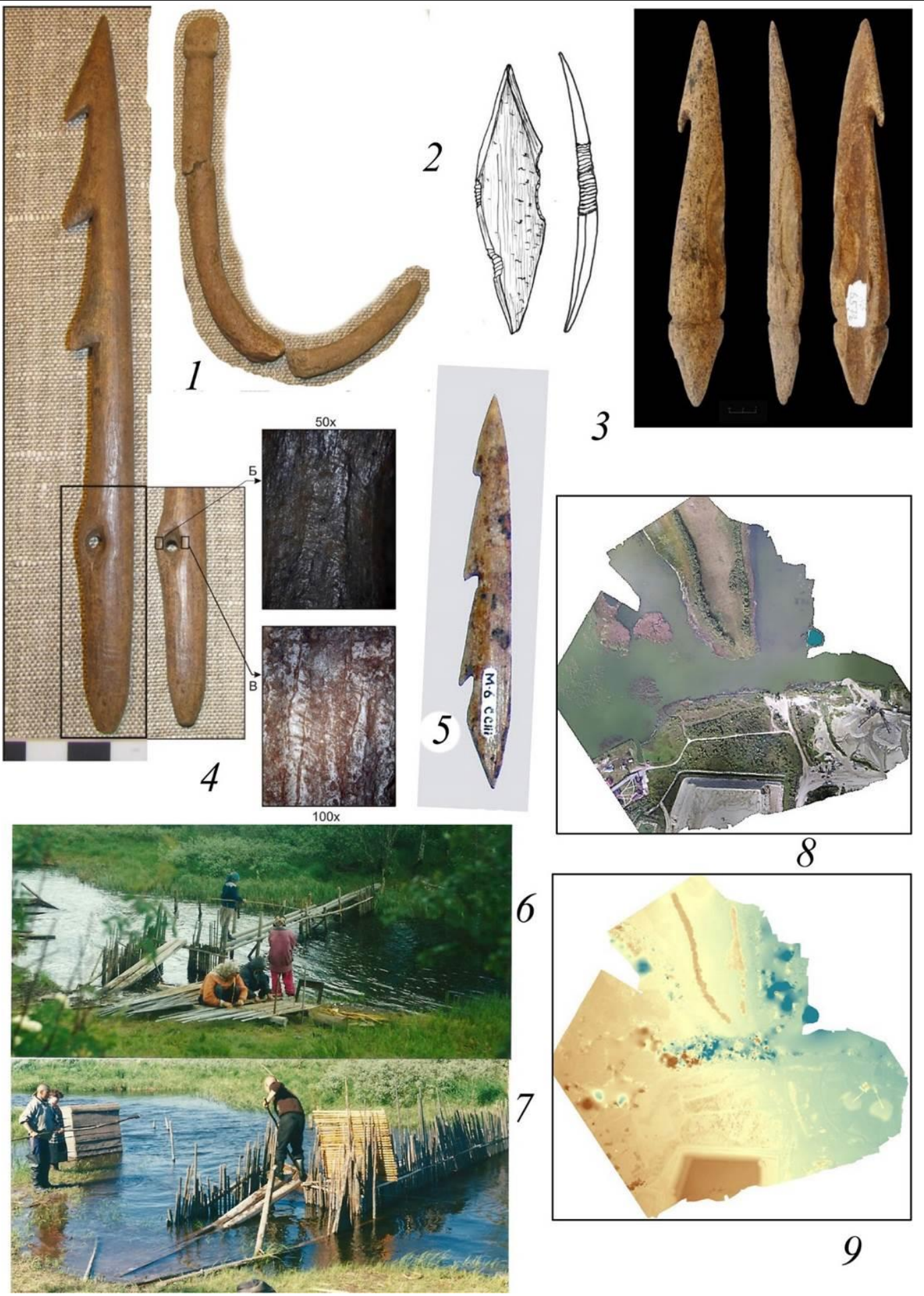

Рисунок 2 - Костяной инвентарь поселения Мергень 6.

1 - крюк из рога; 2- «жерлица»; 3-5- острога и гарпуны. 6, 7- сооружение запора (верховья р. Казым); 8, 9- ортофотопланы южной части Большого Андреевского острова (по О.С. Сизову)

Первая классификация глиняных грузил была сделана М.Ф. Косаревым [8]. К переходному времени от неолита к раннему металлу им отнесены широко встречающиеся на памятниках Притоболья изделия биконической, сигаровидной форм и с раздвоенными («рожковидной» формы) концами (рис. 3: 1-9, 15). Глиняные грузила иногда скоплениями до 45 экз. находят в жилищах и на поселениях, значительное количество их обломков обнаружено по побережью озер, в частности Андреевской озерной системы. Периодизацию глиняных грузил начальных этапов раннего металла предложил Е.Н. Волков [9, с. 6], добавивший еще один тип изделий - стержневидной формы, в некоторых случаях - подквадратной формы в сечении. На наш взгляд, выделенные Е.Н. Волковым грузила наиболее близки к изделиям в виде стержней округлой в сечении формы с небольшим утолщением посередине и, вероятно, их прообразам - биконическим слегка приплюснутым грузилам. В последнее время предлагается развитие переходных от неолита к раннему металлу комплексов в такой последовательности: шапкульские, байрыкские и андреевские $[10 ; 11]$. Учитывая это, периодизацию глиняных грузил Нижнего Притоболья, предложенную М.Ф. Косаревым, следует считать более предпочтительной. Правда, грузила с раздвоенными концами (рожковидные) - самые поздние, в большинстве случаев они встречаются в комплексах металлоносной таш- 
3ax B.A.

Рыболовство в Тоболо-Ишимье в эпоху неолита и раннего металла

07.00.00 - исторические науки и археология

ковской [12;13] и коптяковской культур [14], сформировавшихся, как нам представляется, на основе местных комплексов гребенчато-ямочной и петровской и/или алакульской орнаментальных традиций. В жилище на поселении Чепкуль 5 вместе с коптяковской посудой встречено скопление грузил с раздвоенными концами, среди них глиняный диск с отверстием, а вне скопления - грузило подквадратной формы с одним перехватом (рис. 3: 10) [15]. Рассматриваемые глиняные грузила выходят за пределы Тоболо-Ишимья и встречаются на сопредельных западных и северо-западных территориях горно-лесного Зауралья и бассейна р. Конды в энеолитических комплексах, близких по материалам к лесостепным $[16 ; 17]$.
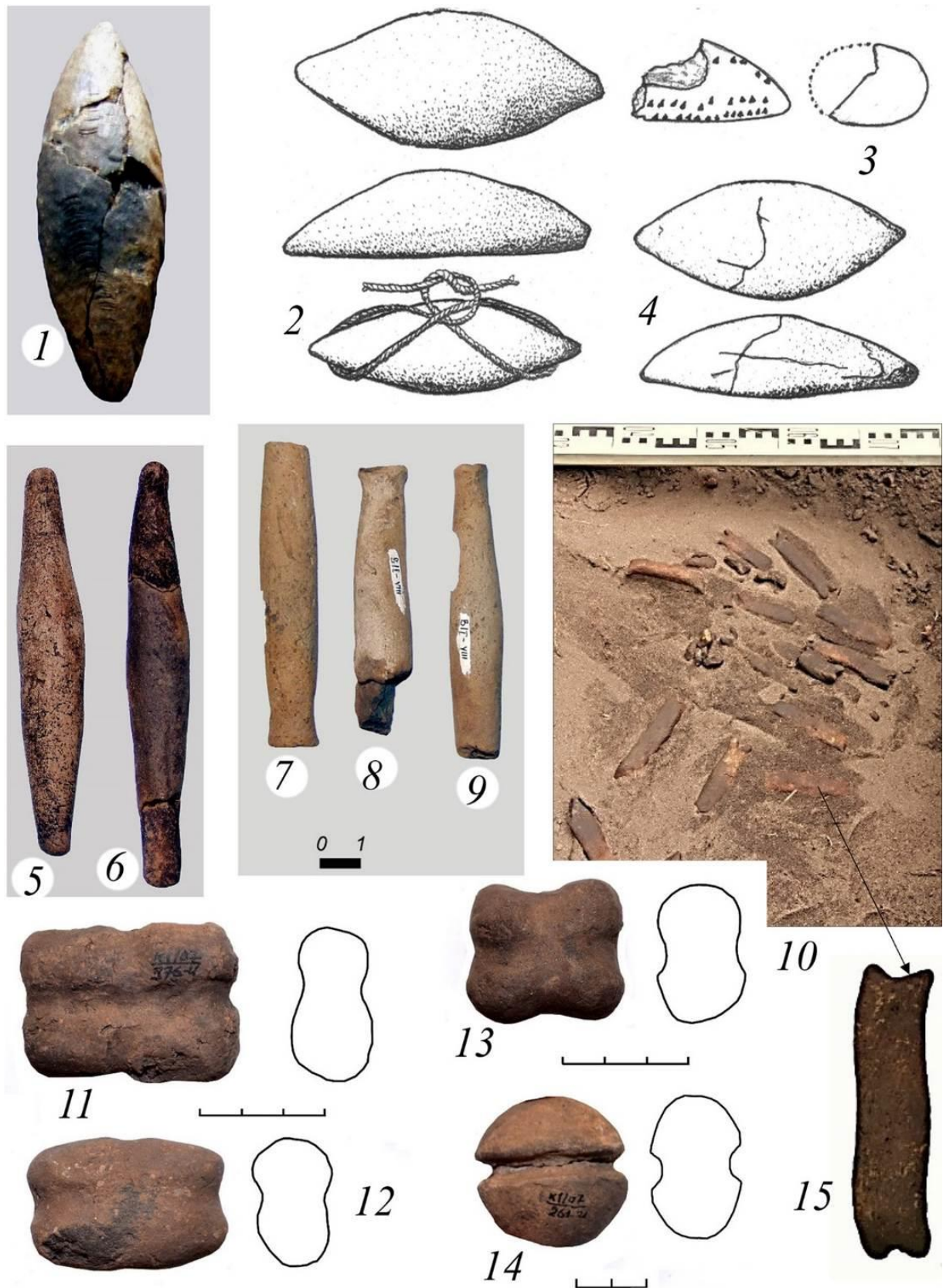

Рисунок 3 - Глиняные грузила разных эпох с поселений III-I тыс. до н.э. Притоболья. 1 - Кочегарово 1; 2-4- Чечкино 2; 5, 6- Малый Байрык 2; 7-9- Велижаны 2; 10, 15 - Чепкуль 5; 11-14- позднебронзовые поселения Притоболья

Коптяковские комплексы в Притоболье демонстрируют своего рода переходный тип экономики от присваивающего охотничье-рыболовческого хозяйства к производящему, в основном скотоводческому, федоровской и позднебронзовых культур. Вероятно, это повлекло изменение орудийного набора, в том числе глиняных грузил для сетей. По федоровским материалам (Дуванское 17, Черемуховый Куст, Курья 1) можно видеть, что на смену глиняным грузилам биконической, сигаровидной и с раздвоенными концами приходят в основном изделия подпрямоугольной формы с одним или двумя перехватами и в виде приплюснутого диска с одним перехватом, которые бытуют преимущественно в позднебронзовое время (рис. 3: 11-14) [18; 19; 20]. Свидетельством рыболовства у федоровского и позднебронзового населения, кроме грузил, являются на некоторых поселениях немногочисленные остатки костей и чешуи рыбы в колодцах (федоровских) и ямах. В отличие от позднебронзовых комплексов, на поселениях переходного времени от бронзы к раннему железу в жилищах, ямах и культурном слое за их пределами встречаются значительные по мощности пласты чешуи, однако отсутствуют глиняные грузила. Учиты- 
вая, что в переходное время произошло слияние населения местных позднебронзовых культур с пришлыми с северных территорий носителями традиции крестовой орнаментации, естественно предположить, наряду с увеличением в хозяйстве доли присваивающих отраслей изменение орудий и методов ловли рыбы.

\section{Результаты исследований и их обсуждение}

В реконструкции способов ловли рыбы древним населением важным, на наш взгляд, является такой фактор, как изменение гидрологического режима водоемов. Он определяет возможность применения различных типов ловушек - запоров, перегораживающих протоки между реками и озерами, плетеных ловушек в виде гимг, сетей или ловушек с использованием крючков. Кроме этого, с колебанием уровня водоемов сопряжены гипсометрическое положение древних поселков и запасы пищевых ресурсов. С высокими отметками террас, при большой наполненности водоемов, связаны боборыкинские, козловские, кокуйские неолитические комплексы атлантического периода, поселения с шапкульскими, байрыкскими и андреевскими материалами, существовавшие в III тыс. до н.э. в начале суббореального периода, ташковские и коптяковские поселки, занимающие приречные и приозерные надпойменные террасы. Высокие участки террас занимают поселки позднебронзового и переходного времени от бронзы к раннему железу. Низкое гипсометрическое положение отмечено для кошкинских и федоровских поселений, начала атлантического и середины суббореального периодов голоцена, что свидетельствует о низком уровне воды в реках и озерах. Ландшафтно-климатические условия, судя по палинологическим данным из торфяников и культурных слоев и гипсометрическому положению древних поселков, менялись: залесенные пространства с обводнением речных и озерных пойм сменяли остепненные территории с пониженным уровнем грунтовых вод. Кроме эпохальных ландшафтно-климатических перестроек большое значение имели циклические колебания гидрологического режима речных и озерных систем. Они вносили свои поправки в системы жизнеобеспечения населения, определяя, в частности в рыболовстве, основные способы и орудия лова.

Судить о запорном рыболовстве в основном приходится по косвенным данным: нахождению древних поселков у перейм, на протоках в озерных системах, где есть возможность сооружать и обслуживать запорные конструкции. Реконструировать изменения береговой линии в древности, волноприбойных уступы, глубину и площадь зеркала озер позволяют ДДЗ (данные дистанционного зондирования Земли), данные батиметрии и ортофотографический метод, а также анализ картографических материалов.

На рассматриваемой территории наиболее изученной является Андреевская озерная система, включающая несколько озер, соединенных протоками с p. Дуван. Изменение гидрологического режима в системе хорошо иллюстрирует карта, составленная С.У. Ремезовым в 1700 г., фиксирующая полноводность озер и остров Абаев (Совр. Большой Андреевский) (рис. 4: 4). Карта 1829 г. Василия Филимонова показывает иную ситуацию - низкую воду в период, когда остров становится полуостровом, ширина перейм и проток сокращается, что способствует по- стройке на них запоров. О понижениях уровня Андреевских озер и уменьшении ширины перейм, например в районе Андреевского острова и Бутурлыжского мыса, свидетельствуют ортофотопланы и батиметрические данные, фиксирующие остатки волноприбойных уступов (рис. 2: 8,9 ; рис. 5: 1, 2). Циклические изменения водного режима в Тоболо-Ишимье приводили к колебаниям продуктивности водоемов, а с другой стороны, к применению различных способов ловли рыбы.

Появление в неолитическое время углубленных долговременных жилищ (в отличие от лесостепных мезолитических комплексов, на которых, скорее всего, существовали наземные жилища типа чума), возможность при малой воде сооружения и обслуживания коллективами загородок на переймах, протоках и речках свидетельствуют об относительной оседлости населения. При присваивающем хозяйстве ее могло обеспечить только рыболовство, причем, вероятнее всего, запорное (рис. 2: 6, 7). Об этом говорит и небольшой набор (гарпуны, остроги, жерлицы) орудий индивидуального лова, отсутствие крючков и грузил для сетей. О наличии последних можно судить лишь по косвенным данным - стандартному размеру рыбы и значительному количеству костей нырковых водоплавающих, в частности чомг, на поселении Мергень 6 [3]. На возможное использование сетей неолитическим населением указывают находки плоских изделий из глины (рис. 4: 3, 5) на поселении Серебрянка 1, во многом подобные современным деревянным «меркам», применяющимся при их вязании [21]. Не исключено, что для вязания сетей служили орудия, интерпретируемые как «иглы» [21]. Однако, на наш взгляд, сетевое рыболовство в условиях низкой воды на неглубоких и сильно зарастающих в большинстве случаях заморных лесостепных озерах Западной Сибири было занятием малопродуктивным и нерациональным. Вспомогательными источниками получения пищи при преобладании запорного рыболовства, скорее всего, были охота на копытных, водоплавающую и боровую дичь, битье рыбы гарпуном, острогой, ловля ловушками, сплетенными из прутьев типа корчаг, гимг и пр.

В постнеолитическое время, в конце IV - начале III тыс. до н.э., в Тоболо-Ишимском междуречье большинство поселков располагаются на краю надпойменных террас, что говорит об изменении ландшафтно-климатических условий и водного режима рек и озер. Суббореальный период характеризуется климатическим непостоянством [22, с. 163; 23], культурные комплексы раннего металла связаны в основном с раннесуббореальным похолоданием (46004100 л.н.), когда увеличиваются увлажненность и повторяемость половодий, что влечет за собой изменение в системе жизнеобеспечения древних коллективов. Шире осваивается кромка побережий: так, на озерах Андреевской системы культурный слой эпохи раннего металла распространяется на сотни метров. Увеличивается количество поселков, уменьшается глубина котлованов сооружений, появляются наземные жилища, что может указывать на возросшую подвижность населения. В инвентаре шапкульских, байрыкских и андреевских комплексов появляются глиняные грузила биконических и сигаровидных форм, а также шлифованные ножи из сланца, удобные для чистки и разделки рыбы (рис. $4: 1,2$ ). Правда, Н.Ю. Кунгурова считает, что они применялись 
3ax B.A.

Рыболовство в Тоболо-Ишимье в эпоху неолита и раннего металла

07.00.00 - исторические науки и археология

при работе с деревом и берестой [24]. Скорее всего, в этот период происходит кризис запорного рыболовства, так как при высокой воде, когда поймы могли оставаться залитыми до середины августа, пользоваться запором становилось сложно, а иногда просто невозможно и неэффективно. Однако запоры могли ставить в устьях небольших речек, как, например, это делали на р. Язевке, впадающей в Андреевское озеро, крестьяне из окрестных деревень [25]. В условиях повышенной обводненности (рис. 5: 3) лесостепных водоемов продуктивной, скорее всего, становится ловля рыбы различными ловушками, неводами и, возможно, сетями, хотя в отношении последних имеются некоторые вопросы, относящиеся к их параметрам и составным частям, в частности грузилам, а также технологические, связанные с плетением, изготовлением тонких и крепких нитей. Так, обращает на себя внимание разный размер и вес ранних биконических грузил и более поздних изделий сигаровидной и рожковидной форм, что, возможно, свидетельствует о применении их в разных природных средах и, вероятно, в разных ловушках. Биконические могли использоваться в рыболовных сетях, а меньшие по размеру и весу сигаровидные и рожковидные грузила - в ловушках подобных сетям, но предназначенных для ловли водоплавающей дичи.
Отсутствие материальных свидетельств прядения, в частности образцов нитей и глиняных пряслиц, в комплексах начала раннего металла и их первое появление на поселениях скотоводов андроновского времени ставят вопросы о сырьевых ресурсах, качестве нитей и их использовании у доскотоводческого населения Тоболо-Ишимья. Наличие растений (крапива, конопля, хмель и др.) для получения соответствующего сырья, а также, например, известное по этнографическим данным применение деревянных пряслиц предполагает существование прядения, плетения и, вероятно, примитивного ткачества в рассматриваемую эпоху. Однако технология, процесс изготовления и параметры нитей и их использование для вязания, в частности, сетей мало изучены. По реконструкции И.Г. и Т.Н. Глушковых, для изготовления ткани, отпечатки которой встречаются на посуде, в том числе из конопли и крапивы, брались нити толщиной 1,2-1,5 мм [26, с. 95-108]. Мелкоячеистые сети, связанные из нитей такой толщины, малоэффективны; с нитями в 1,2-1,5 мм продуктивны, на наш взгляд, только крупноячеистые изделия для ловли крупной рыбы, в том числе карася, или невода с мелкой ячеей.
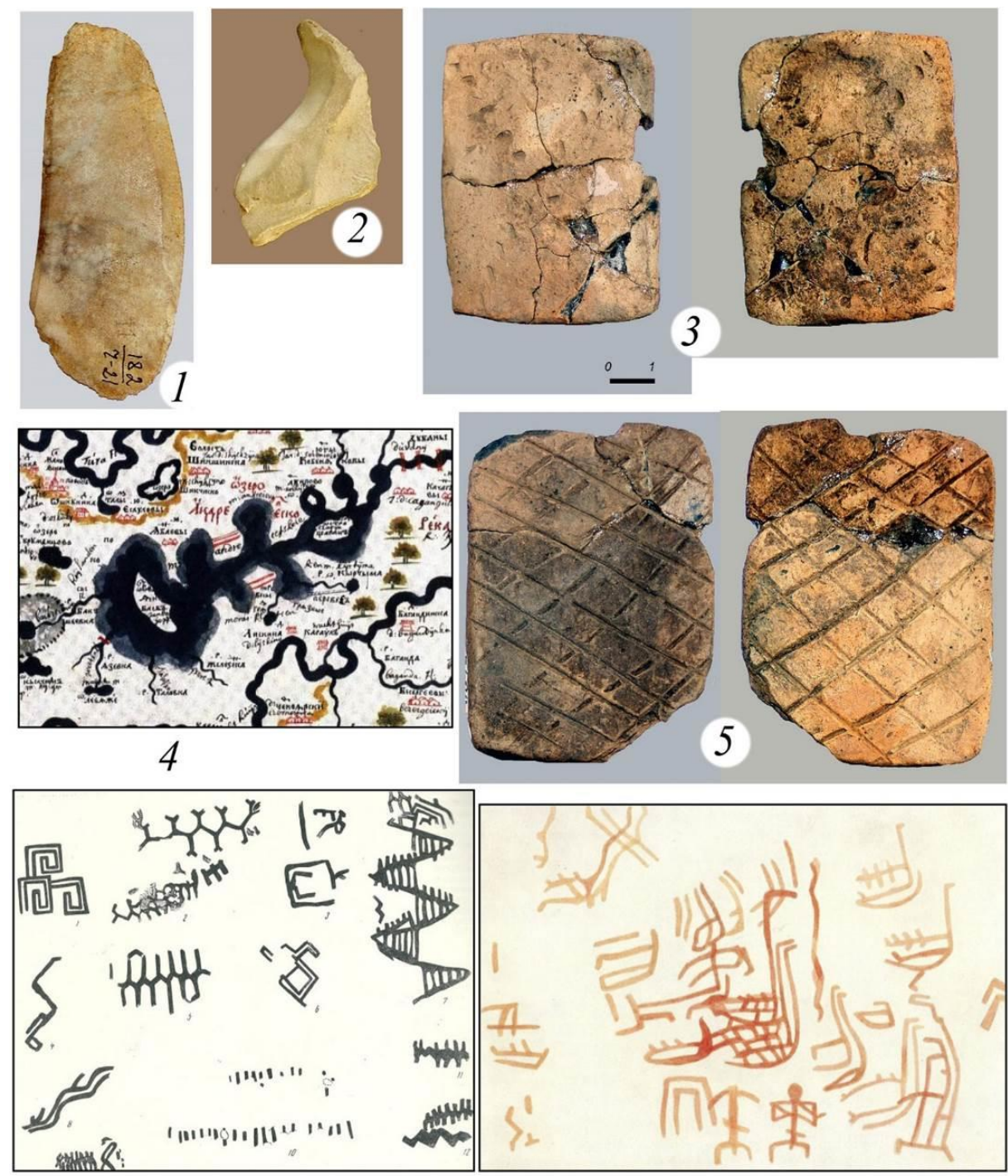

6

Рисунок 4 - Шлифованные ножи. 1 - Чепкуль 21; 2- Велижаны 2;

4- фрагмент карты системы Андреевских озер С.У. Ремезова 1700 г.;

3, 5- «глиняные таблички» с поселения Серебрянка 1; 6, 7- фрагменты писаниц Урала 

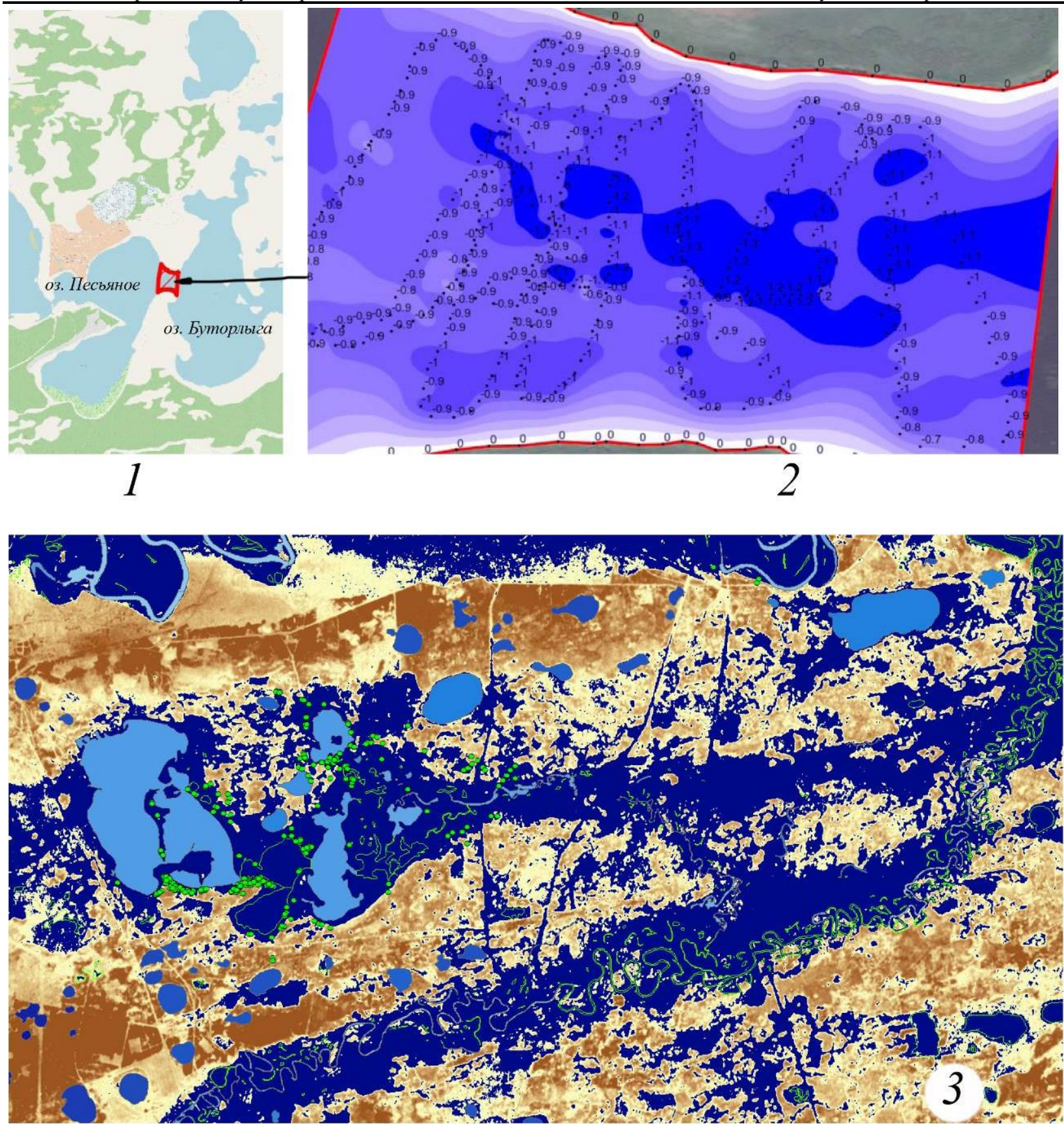

Рисунок 5 - Материалы к гидрологии системы Андреевских озер. 1 - место батиметрических исследований; 2 - глубины переймы между озерами Песьяное и Буторлыга (по Н.В. Приходько);

3- компьютерная модель ложбин древнего стока. Уровень подтопления - 57 м (по О.С. Сизову)

Судя по находкам на поселениях скоплений грузил разных форм (до 45 шт.), сети или же другие типы ловушек, в которых они применялись в III тыс. до н.э., были небольшими. В условиях обводненности, подтопления обширных пойменных пространств, по нашему мнению, наиболее оптимальным и производительным мог быть лов рыбы не сетями, а неводами.

Не исключено, и это, на наш взгляд, подтверждается рисунками писаниц (рис. 4: 6, 7) и изображениями водоплавающих птиц на керамической посуде [27], что при обилии в озерных системах гусей, уток практиковалась охота на них во время линьки. Птица загонялась в загородки, в том числе из сетей с грузилами небольшого веса (в воздушной среде), подобными по форме изделиям сигаровидной и рожковидной форм. Такой способ охоты, вероятно, широко применялся на Урале в древности, что зафиксировано на писаницах [28, с. 64-76]; известен он и на ле- состепных озерах у барабинских татар [29]. Возможно, обломки глиняных грузил сигаровидной и рожковидной форм, встречающиеся по берегам озер Андреевской системы вне поселений, как раз свидетельствуют о таком промысле водоплавающей дичи. Кроме того, нельзя исключать применение ловушек в виде сетей с небольшими грузилами, натянутых вертикально на определенной высоте, при ловле уток на их перелетах. Это так называемые перевесы, которые использовались, например, на побережье тех же Андреевских озер в конце XVII - начале XVIII в. и отмечены на карте С. Ремезовым [30].

Образ водоплавающей птицы широко встречается в искусстве древнего населения северо-западных и северо-восточных областей Восточной Европы и Западной Сибири. Не случаен, на наш взгляд, факт сосуществования в пределах III - начала II тыс. до н.э. рассматриваемых грузил и изображений на посуде и 
3ax B.A.

Рыболовство в Тоболо-Ишимье в эпоху неолита и раннего металла

07.00.00 - исторические науки и археология

на писаницах Урала. Изображения птиц начала периода достаточно реалистичны. В конце же, когда в комплексах, например, коптяковской культуры, присутствуют как рожковидные, так и подпрямоугольной формы грузила с одним, а позже и двумя перехватами для крепления [27; 31], изображения становятся крайне стилизованными, в виде ряда Z-образных и зеркальных им фигур [32, рис. 7: 9]. С появлением производящего хозяйства на территории Тоболо-Ишимья грузила биконической, сигаровидной и рожковидной форм, характерные для начального периода эпохи раннего металла (III - начала II тыс. до н.э.), полностью исчезают. В последующие, федоровский и позднебронзовый периоды, в комплексах пахомовской, бархатовской и сузгунской культур начинают доминировать глиняные изделия подпрямоугольной формы с одним или двумя перехватами или дисковидные с одним перехватом для крепления бечевы. Вопрос о том, какова была основа для их типологического развития, требует разработки, но не исключено, что прообразом грузил подпрямоугольной формы являлись рожковидные изделия, у которых сократилась длина, увеличилась ширина и изменилась форма сечения.

Наличие в культурном слое поселений эпохи бронзы костей, чешуи рыбы и грузил свидетельствует о существовании в системе производящей скотоводческой экономики в определенной доле сетевого рыболовства; оно бытовало, впрочем, и в обществах последующих периодов: переходного от бронзы к железу времени, эпохи раннего железа, раннего и позднего средневековья и в историческое время. Однако во все эти периоды, в связи с колебанием гидрологического режима речных и озерных систем, вероятно, применялись разные способы лова и ловушки. Наряду с костями и чешуей рыбы, глиняными грузилами на памятниках эпохи бронзы находят артефакты, подтверждающие занятия прядением и ткачеством. В этот период широкое распространение получили глиняные пряслица, обнаружены остатки шерстяной и ткани из растительных волокон. В переходный период от эпохи бонзы к раннему железу, при обилии в суглинистых культурных слоях поселений костей и чешуи рыбы, глиняные грузила отсутствуют. Встречается огромное количество чешуи и костей в ямах этого времени на поселении Мергень 6 , перекрывающих слои раннего металла и неолита. Исходя в основном из двухкомпонентности культур переходного времени, одним из слагаемых которых были комплексы носителей традиции крестовой орнаментации, проникающие с северных территорий, можно предположить, что на смену ловли рыбы сетями пришли иные, новые методы или же старый - с помощью запора. Примечательно, что комплекс переходного времени находился там же, где и более ранние поселения, на которых отсутствовали грузила для сетей, но в обилии отмечались костные остатки рыбы и некоторые орудия ее лова. Мы не исключаем, что население переходного времени от бронзы к железу при ловле рыбы у истока р. Мергеньки использовали запор как одно из основных средств добычи, дающее стабильное количество продукта. Аналогичный способ лова рыбы до настоящего времени широко применяется обскими уграми, сохраняющими традиции, уходящие в глубокую древность: так, колья заострялись на расстояние до 0,6 м от края в виде шестиугольника в сечении и переплетались с помощью распущенных кедровых корней, вымоченных в реке. Близкие технологии и ловушки известны еще с мезолитического времени на территории Восточной Европы и Европейского Севера [33; 34].

\section{Выводы}

За достаточно длительный период от VII-VI до середины I тыс. до н.э. системы жизнеобеспечения, а в них рыболовство видоизменялись в разные археологические периоды в зависимости климатических условий и колебаний гидрологического режима водоемов. На ранних этапах неолита, в условиях низкой обводненности, на территории лесного ТоболоИшимья основной составляющей системы жизнеобеспечения оседлого населения было запорное рыболовство, крупную рыбу добывали также гарпунами и острогами; отсутствие на поселениях грузил и рыболовных крючков свидетельствует о нерациональности соответствующих способов лова рыбы. Изделие из рога (рис. 2: 1), интерпретируемое как рыболовный крючок [21, с. 20], скорее всего, является крюком, с помощью которого доставали рыбу, особенно щуку и окуня, способных поранить руки, из ловушек. Аналогичные, но деревянные крючья применялись хантами для вынимания рыбы из морд на р. Вах [35, с 115]. Вспомогательное значение имела охота на крупных животных, водоплавающую и боровую дичь. В начале III тыс. до н.э., в эпоху раннего металла, в условиях начинающегося увлажнения и участившихся половодий происходят изменения в системах жизнеобеспечения населения: появляются постройки наземного типа, шире осваиваются побережья озер и рек, увеличивается количество поселков, что, вероятно, свидетельствует об их сезонном характере и освоении нетрадиционных мест лова рыбы и охоты. Появление грузил биконической, сигаровидной и рожковидной форм указывает на использование новых средств - сетей и неводов при сохранении прежних - различного рода ловушек, плетенных из прутьев, гарпунов и острог. Вместе с тем сети с подобного рода грузилами могли использоваться при загонной охоте на водоплавающую дичь во время линьки, о чем, возможно, позволяют судить орнамент на глиняной посуде и изображения на писаницах Урала. В первой половине II тыс. до н.э. грузила названных форм исчезают. В эпоху бронзы вначале используются глиняные грузила подпрямоугольной формы с одним или двумя перехватами, а в период финальной бронзы - в виде диска с перехватом посередине. Развитие форм глиняных грузил в III-I тыс. до н.э. представлено на рис. 6. В переходное время от бронзы к раннему железу, с продвижением носителей традиции крестовой орнаментации на юг, глиняные грузила исчезают; наличие в культурных слоях поселений этого времени большого количество костей рыбы и чешуи явно свидетельствует о значительной роли рыболовства в хозяйстве этих обществ. Нахождение некоторых поселений переходного времени на местах поселков неолитического времени, возможно, «намекает» на возврат к ловле рыбы с помощью запоров. 


\begin{tabular}{l|l|l|}
\hline ВРЕМЯ & КУЛЬТУРА \\
\hline \multirow{2}{*}{ ІІІ ТЫС. } \\
ДО Н.Э.
\end{tabular}

Рисунок 6 - Развитие формы глиняных грузил в III-I тыс. до н.э. 1 - Кочегарово 1;

2, 3- Малый Байрык 2; 4-6- Велижаны 2;

7-Заводоуковское 13; 8, 9- Чепкуль 5;

10-13 - позднебронзовые поселения Притоболья

\section{Список литературы:}

1. Шнитников А.В. Внутривековые колебания уровня степных озер Западной Сибири и Северного Казахстана и их зависимость от климата: Труды лаборатории озероведения АН СССР. Т. 1. Л.: Изд-во АН СCCР? 1950. 185 c.

2. Шнитников А.В. Изменчивость общей увлажненности материков Северного полушария // Зап. Географического общества СССР. Вып. 16. М.-Л., 1957. $245 \mathrm{c}$.

3. Косинцев П.А., Некрасов А.Е. Промысловая деятельность людей из поселений, расположенных на берегу озера Мергень (Мергень 5 и 6) в неолите и энеолите // Экология древних и современных обществ. Тюмень: Изд-во ИПОС СО РАН, 1999. C. $100-104$.

4. Чикунова И.Ю. Комплекс археологических памятников на р. Иске // Вестник археологии, антропологии и этнографии. Тюмень: Изд-во ИПОС СО РАН, 2004. Вып. 5. С. 207-213.

5. Дмитриев П.А. Вторая Андреевская стоянка // Труды ГИМ. М., 1938. Вып. 7. С. 93-110.

6. Матвеев А.В., Зах В.А., Ларин С.И., Дрябина Л.А., Матвеева Н.П. Доисторические культуры и палеография Мергенского археологического микрорайона // Археологические микрорайоны Западной Сибири. Омск: Омск. ун-т, 1997. С. 76-114.

7. Скочина С.Н. Хозяйство жителей энеолитического поселения Мергень 6 // Вестник археологии, антропологии и этнографии. Тюмень: Изд-во ИПОС CO РАН, 2004. № 5. С. 27-31.

8. Косарев М.Ф. Древнейшие грузила Нижнего Притоболья // История, археология и этнография Сибири. Томск: ТГУ, 1979. С. 15-25.

9. Волков Е.Н. Глиняные грузила Тюменского Притоболья (энеолит и ранний бронзовый век) // Вестник археологии, антропологии и этнографии. Тюмень: Изд-во ИПОС СО РАН, 2009. № 10. С. 4-11.

10. Зах В.А., Скочина С.Н., Пархимович С.Г. Грунтовый могильник Чепкуль 21 на севере Андреевской озерной системы // Вестник археологии, антропологии и этнографии. Тюмень: Изд-во ИПОС СО РАН, 2005. Вып. 6. С. 24-42.

11. Зах В.А., Зимина О.Ю. О взаимодействии андреевской и липчинской культур в Нижнем Притоболье (по материалам поселения Велижаны 1) // Вестник археологии, антропологии и этнографии. Тюмень: Изд-во ИПОС СО РАН, 2018. Вып. 2 (41). C. 24-42.

12. Ковалева В.Т. Взаимодействие культур и этносов по материалам археологии: поселение Ташково 2. Екатеринбург: Изд-во УрГУ, 1997. 131 с.

13. Ковалева В.Т., Рыжкова О.В., Шаманаев А.В. Ташковская культура: поселение Андреевское озеро 13. Екатеринбург: Изд-во УрГУ, 2000. 160 с.

14. Зах В.А. Коптяковская культура в Нижнем Притоболье // Вестник археологии, антропологии и этнографии. № 2 (17). Тюмень, 2012. С. 29-40.

15. Зах В.А., Костомаров В.М., Илюшина В.В., Рябогина Н.Е., Иванов С.Н., Костомарова Ю.В. Коптяковский комплекс поселения Чепкуль 5 // Вестник археологии, антропологии и этнографии. 2014. № 1 (24). C. 36-49.

16. Чаиркина Н.М. Энеолит Среднего Зауралья. Екатеринбург: Изд-во УрО РАН, 2005. 313 с.

17. Кокшаров С.Ф. Памятники энеолита севера Западной Сибири. Екатеринбург: Изд-во НПМП «Волот», 2009. $272 \mathrm{c.}$

18. Стефанов В.И., Корочкова О.Н. Андроновские древности Тюменского Притоболья. Екатеринбург: Полиграфист, 2000. 108 с.

19. Зах В.А. Поселок древних скотоводов на Тоболе. Новосибирск: Наука, 1995. 96 с.

20. Зах В.А., Рябогина Н.Е., Илюшина В.В., Иванов С.И., Мурзина Е.И. Федоровский поселок Курья 1 в системе Андреевских озер // Вестник археологии, антропологии и этнографии. Вып. 1 (20). Тюмень: Изд-во ИПОС СО РАН, 2013. С. 10-23. 
21. Скочина С.Н. Орудия охоты и рыболовства в неолите Нижнего Приишимья // Вестник археологии, антропологии и этнографии. Тюмень: Изд-во ИПОС CO PAH, 2014. № 2 (25). С. 15-25.

22. Хотинский Н.А. Голоцен Северной Евразии. М.: Наука, 1977. 200 с.

23. Хотинский Н.А., Немкова В.К., Сурова Т.Г. Главные этапы развития растительности и климата Урала в голоцене // Археологические исследования севера Евразии. Свердловск: Изд-во УрГУ, 1982. C. $145-153$.

24. Кунгурова Н.Ю. Шлифованные ножи Верхнего Приобья // Культура древних народов Южной Сибири. Барнаул, 1993. С. 30-33.

25. Зах В.А. Андреевская озерная система (гидрология и использование природных ресурсов по археологическим и картографическим материалам XVIII-XX вв.) // Вестник археологии, антропологии и этнографии. Тюмень: Изд-во ИПОС СО РАН, 2016. № 4 (35). С. 15-25.

26. Глушков И.Г., Глушкова Т.Н. Текстильная керамика как исторический источник (по материалам бронзового века Западной Сибири). Тобольск: Издво ТГПИ, 1992. $130 \mathrm{c}$.

27. Гурина Н.Н. Водоплавающая птица в искусстве неолитических лесных племен // Краткие сообщения Института археологии. М.: Наука, 1973. Вып. 131. С. 36-45.

28. Чернецов В.Н. Наскальные изображения Урала. Свод археологических источников. В. 4-12 (2). $120 \mathrm{c}$.

\section{FISHERY IN THE TOBOL-ISHIM INTERFLUVE IN THE NEOLITHIC AND EARLY METAL AGE}

(C) 2018

Zakh Viktor Alekseevich, doctor of historical sciences, head of Archaeological and Natural Reconstructions Department

Tyumen Scientific Center of Siberian Branch of the Russian Academy of Sciences (Tyumen, Russian Federation)

Abstract. Landscapes of the Tobol-Ishim interfluve were not stable in the Holocene and varied from forests and drowned floodplains at the beginning of the V and III millennia BC to steppificated territories with a lowered water level at the beginning of the Atlantic Period and in the middle of the Subboreal Period, which determined the main types of economic activities, one of them was fishing. Changes in hydrological regime of water bodies influenced the methods of fishing, including the use of different traps. Thus, in the Neolithic, when the water level decreased, the location of settlements in the system river-creek-lake (for example, Mergen 6), a large number of fish bones, bone harpoons, fishing spears, fishing tackles for catching pike and a total absence of plummets were indicative of individual fishing for large fish and, perhaps, of stop net fishery, which was facilitated by a decrease in the width of watercourses and tombolos. Stop net (stake net) fishery led to a settled lifestyle of the population, collective activities and the emergence of long-term settlements with deep foundation pits of dwellings. When the water level in rivers and lakes increased and floods became more frequent, the life support system changed, the population began to develop coasts more widely, its mobility increased, and they started to build framed above-ground dwellings. Following those changes, biconic, cigar-shaped, and corniculate plummets emerged in the Tobol River Basin and on the adjacent western and north-western territories in the III and early II millennium BC. When the water level was high, it was efficient to fish using traps, seines and, probably, nets, although the latter could also be used in drive hunting for shedding geese and ducks. Subrectangular plummets with one or two ties for fastening, and disk-shaped plummets with a tie in the center had been prevailing since the beginning of the II millennium BC; they existed until the first third of the I millennium BC. This period, the transition time from the Bronze Age to the Early Iron Age, is characterized by the absence of clay plummets, while there are large accumulations of fish scales and bones in the settlement layers. We can suppose that the population of that time (local Late Bronze Age population, mixed with northern migrants who made utensils with cross ornamentation) switched from net fishing to stop net fishing.

Keywords: Western Siberia; Tobol-Ishim interfluve; lake systems; Neolithic; Early Metal Age; late bronze; transition time from bronze to early iron; hydrological regime; wave-surfacing ledges; stop net and net fisher; constipation (zakol); harpoons; traps; clay plummets; hunting for waterfowl. 